\title{
Dental Age Estimation by Demirjian's and Nolla's Method in Children of Jorpati, Kathmandu
}

\author{
Sanskriti Khanal, ${ }^{1}$ Jemish Acharya, ${ }^{2}$ Priyanka Shah ${ }^{1}$ \\ ${ }^{1}$ Department of Pedodontics ,Nepal Medical College, Kathmandu, Nepal, ${ }^{2}$ Department of Global Health, Mahidol \\ University, Bangkok, Thailand.
}

\begin{abstract}
Background: Growing individuals not only differ in the timing of the maturational events, but also in the sequence of these events. Age is one of the essential factors, which play an important role in every aspect of life like in clinical, medico-legal, forensic and anthropological applications and in planning treatment of orthodontic and pedodontic patients. The aim of the study was to determine dental age from orthopantomogram using Demirjian's method and Nolla's method and to evaluate the interrelationship between chronological and dental age according to both these methods. Materials and Methods: A cross sectional study was carried out in 177 orthopantomograms of the patient aged between 5 to 15 years. Dental age estimation was done with Demirjian's and Nolla's method. Results: The mean chronological age $10.14 \pm$ 3.16 compared with the mean Demirjian age $9.58 \pm 3.39$ was statistically non significant $p>0.05$ whereas comparision with mean Nolla age $7.88 \pm 1.56$ was significant statistically. Conclusions: Both methods showed delayed dental age compared to chronological age. Demirjian's method was more applicable to assess the dental age in Nepalese children compared to Nolla's method.
\end{abstract}

Keywords: chronological age; dental age; Demirjian's method; Nolla's method.

\section{INTRODUCTION}

Growing individuals differ in the timing and sequence of the maturational events. The age of an individual has a significant role in clinical, medico -legal, forensic and anthropological applications. ${ }^{1}$ In instances where chronological age is unknown, undocumented or missing, several growth parameters based on skeletal indicators such as hand-wrist bone ossification, changes in pubic symphysis, fusion of cranial sutures, dental maturation, and somatic indicators (like menarche and endocrinal changes) are utilized for probable age estimation. ${ }^{2}$ The assessment of age is useful in planning treatment of orthodontic and pedodontic patients, and in forensic medicine and forensic odontology. ${ }^{3}$

Dental age may be assessed by tooth eruption timing or by the progress of tooth calcification of a single tooth or a group of teeth. There are studies that have been conducted in different Nepalese population to assess the teeth eruption timing and sequence. ${ }^{4,5,6}$ These studies have shown that the tooth eruption of primary ${ }^{4,5}$ and permanent teeth ${ }^{6}$ in Nepalese children is delayed when compared to the western population. Many studies have concluded that tooth formation is a more reliable indicator of dental maturity than gingival emergence or eruption. ${ }^{1}$ The limitations of tooth eruption in dental age assessment are; it is altered by local factors such as lack of space, premature loss of primary teeth, crowding of permanent teeth, and decayed teeth and systemic factors like nutritional factors. ${ }^{7}$ Tooth development is a useful measure of maturity since it represents a series of recognizable events that occur in the same sequence from an initial event to a constant end point and the progressive sequence of their eruption in the oral cavity ${ }^{8}$ and neither the tooth development is affected by the nutritional condition compared to other maturational events of an individual. ${ }^{9}$ The objective of this study was to estimate the dental age using orthopantomogram with Demirjian and Nolla's method among Nepalese children aged 5 to 15 years visiting a dental hospital in Jorpati, Kathmandu, Nepal.

\section{MATERIALS AND METHODS}

This was hospital based cross-sectional study conducted in the Department of Pedodontics and Preventive Dentistry, Nepal Medical college, Attarkhel, Jorpati from January 2017 to December

Correspondence: Dr. Sanskriti Khanal, Nepal Medical College, Attarkhel, Kathmandu, Nepal. Email:sans212@gmail.com. Phone: +977-9849693269. DOI: $\quad 10.3126 /$ jemsn.v14i3.20733.

Article received: 2018-08-10. Article accepted: 2018-09-20. 
2017. Ethical clearance for the study was obtained from the Institutional Ethical Committee. Using the hospital records, from the total patients visiting the department in a one year time period , 30\% was taken to estimate the minimum sample size. All patients presenting to the dental department in Nepal Medical College were included until the required sample size was achieved. An additional $20 \%$ was taken to cover withdrawal issues after which a total of 177 subjects ( 81 girls and 96 boys) between the age group of 5 and 15 years were enrolled. From among the six dental colleges in Kathmandu valley, Nepal Medical College was chosen purposively. The patients visiting the dental OPD requiring Orthopantomogram examination for the diagnosis and treatment plan with a full complement of mandibular permanent teeth (erupted or unerupted),physically healthy and well-nourished, nonsyndromic children were included.

Those who were unwilling and did not give consent for the radiographic examination, an unclear orthopantomograph or image deformity affecting left mandibular permanent tooth visualization, patients with systemic diseases, congenital anomalies like cleft lip and cleft palate, dental abnormalities, any permanent teeth extractions, history of trauma or injury to face and gross dental pathology were excluded from the study.

For radiographic procedures, a digital panoramic machine (Rotagraph EVO, panoramic and cephalometric machine, VILLA SISTEMI MEDICALI) with KVPA 64-68, mA-6 and exposure time $13.8 \mathrm{sec}$ was used.

Examination was performed by a single trained, qualified Pedodontist at the Department of Pedodontics, NMC. Chronological age of each patient was determined as provided by the parents in the demographic records. Dental age estimation was based on the development of seven left permanent mandibular teeth except third molar. All OPG were examined by a single examiner. The examiner was blinded with regards to the chronological age of the patient.

\section{Demirjian's method}

Seven teeth present on the left side of the mandible were taken into consideration. Tooth formation was divided into ten stages. ${ }^{10}$ Each stage was given a specific biological weighted score as given by Demirjian et al and the sum of the score provided an estimation of subject's dental maturity. The overall maturity score was then converted to dental age using the available tables for boys and girls which was on the scale of $0-100 .^{10}$

\section{Nolla's method}

Nolla had described the stages of dental development into ten stages beginning with absence of tooth crypt till the completion of root formation, through which all teeth passes during its developmental stage. Each stage also has a numerical score. ${ }^{1}$ In this study the mandibular left seven teeth were given these scores. The obtained scores were totalled to give a combined 'sum of stages' score, that was then divided by the number of teeth taken into consideration to give the dental age. $^{3}$

\section{Data Analysis}

Data Entry and analysis was done using Statistical Package for Software Science (SPSS Version 16.0). Descriptive statistics was calculated for mean and standard deviation. Independent samples t-test was done to compare means between the samples.

\section{RESULTS}

This study was conducted among 177 children visiting Dental OPD who required orthopantomogram for the diagnosis and treatment plan. There were 81 girls and 96 boys who full filled the criteria (Table 1). The OPG of these children was assessed for the dental age using Demirjian and Nolla method.

\begin{tabular}{|lcc|}
\hline \multicolumn{3}{|c|}{ Table 1. Distribution of children in study. } \\
\hline Gender & $\mathrm{N}=177$ & Percent \\
Boys & 96 & $54.2 \%$ \\
Girls & 81 & $45.7 \%$ \\
\hline
\end{tabular}

The chronological mean age (CA) of the studied population was $10.14 \pm 3.16$. Mean age of the boys and girls was $9.54 \pm 3.12$ and $10.82 \pm 3.09$ respectively. Mean age estimated by Demirjian (DA) method for the total children was 9.58 \pm 3.39 , for boys $8.93 \pm 3.33$ and for girls 10.34+3.32.Mean age estimated by Nolla estimation (NA) method for the total children was $7.88 \pm 1.56$, for boys $7.51 \pm 1.53$ and for girls $8.31 \pm 1.49$ (Table 2).

\begin{tabular}{|c|c|c|c|c|}
\hline & $\mathbf{N}$ & $\begin{array}{l}\text { Mean } \\
\text { CA (SD) }\end{array}$ & $\begin{array}{l}\text { Mean } \\
\text { DA (SD) }\end{array}$ & $\begin{array}{l}\text { Mean NA } \\
\text { (SD) }\end{array}$ \\
\hline Total & 177 & $\begin{array}{l}10.14 \\
(3.16)\end{array}$ & $\begin{array}{l}9.58 \\
(3.39)\end{array}$ & $7.88(1.56)$ \\
\hline Boys & 96 & $\begin{array}{l}9.54 \\
(3.12)\end{array}$ & $\begin{array}{l}8.93 \\
(3.33)\end{array}$ & $7.51(1.53)$ \\
\hline Girls & 81 & $\begin{array}{l}10.82 \\
(3.09)\end{array}$ & $\begin{array}{l}10.34 \\
(3.32)\end{array}$ & $8.31(1.49)$ \\
\hline
\end{tabular}


The mean of the chronological age (CA) was compared to the mean estimated age by Demirjian method (DA) and Nollas (NA) method using paired t-test. Mean chronological age (CA) was compared to mean Demirjian age(DA) it was statistically non -significant whereas when compared with mean Nolla age (NA) it was statistically significant. Comparision of mean of Demirjian age with Nolla age was statistically significant (Table 3 ).

\begin{tabular}{|l|l|l|l|}
\hline \multicolumn{4}{|l|}{$\begin{array}{l}\text { Table 3. Comparison of the mean chrono- } \\
\text { logical age with dental age ( estimated by } \\
\text { Demirjian's and Nolla's method). }\end{array}$} \\
\cline { 1 - 3 } & Mean & SD $( \pm)$ & p value \\
\hline Chronological age (CA) & 10.14 & 3.16 & \multirow{2}{*}{$>0.05$} \\
\cline { 1 - 3 } Demirjian age (DA) & 9.58 & 3.39 & \\
\hline Chronological age (CA) & 10.14 & 3.16 & \multirow{2}{*}{$<0.05$} \\
\hline Nolla age (NA) & 7.88 & 1.56 & \multirow{2}{*}{$<0.05$} \\
\hline Demirjian age (DA) & 9.58 & 3.39 & \\
\cline { 1 - 3 } Nolla age (NA) & 7.88 & 1.56 & \\
\cline { 1 - 3 }
\end{tabular}

\section{DISCUSSION}

Dental age correlates closely with chronological age in a person's development. ${ }^{11}$ Environmental, climatic, genetic, hormonal and nutritional factorcan influence the development of each human's organs ${ }^{12}$ but tooth developmental process is found to have no influence from the nutritional status $^{9}$ and are controlled more by the genetic factors than environmental factors. ${ }^{13}$ There are various methods for the age estimation. ${ }^{14}$ Age estimation from teeth by radiological analysis in both children and adolescents has wide applications in several scientific and forensic fields. ${ }^{15}$

In this study the mean chronological age of the children was compared with the mean age estimated by Demirjian's method and Nolla's method. Both methods showed delayed dental age compared to chronological age in the studied population but not statistically significant. Similar result was reported by Nyachhon et al., when the mean dental age by Demirjian's method was compared to the chronological age in Nepalese children. ${ }^{16}$ Mohammed et al., evaluated the chronological age with the dental age in 660 South Indian children of 9 to 20 years and found that there was statistically difference where the dental age was underestimated than the chronological age. ${ }^{17}$ Whereas over-estimation has been reported by Koshy et al., ${ }^{18}$ and Prabhakar et al., ${ }^{8}$ in South Indian children and Willems et al in Belgian

\section{Caucasian children. ${ }^{19}$}

In this study the females showed early maturation compared to the boys in both Demirjian's and Nolla's methods but was not statistically significant. Similar results were found in another studies. Sachan et al., have reported that amongst 90 children aged 9 to 13 years, females were advanced in the dental maturity or dental age compared with the males when the calcification of the canine was assessed by Nolla's method but was not statistically significant. ${ }^{1}$ In another study in Indian children females were more advanced in skeletal maturation than males. ${ }^{7,8}$ The dental age was more advanced in girls in Romanian children, whereas in boys just the 6-7 and 8-9 age groups presented a more advanced dental age. ${ }^{20}$ Gupta et al., reported that Demirjian's methods revealed non significant results whereas the same comparison for Nolla's method revealed significant results $(p<0.05)$. It was found that Demirjian's is a much more reliable method of age estimation as compared to Nolla's method in the adolescents of Uttarpradesh, India. ${ }^{11}$ Sinha et al., reported that Demirjian's method was found to be more applicable to assess the dental age in North Indian children children compared to Nolla's method. ${ }^{3}$ In this studied population we found that the Demirjian's method of dental age estimation was not different statistically however comparision with Nolla's method showed statistically significant difference.

Nur et al., have compared the mean dental age according to the Demirjian and Nolla methods to the mean chronological age in 673 Northeast Turkish children. They reported that the applicability of the Nolla's method was more accurate than the Demirjian's method in Turkish population. ${ }^{21}$. Jurca et al., showed that Demirjian's method has some limitations for a Romanian population, and that these standards are applicable only in certain age groups. ${ }^{20}$

Demirjian et al., proposed dental maturity scores from a French-Canadian population and this has served as a reference dataset for evaluation of age for various population groups. ${ }^{21}$ This method has been utilized in determination of dental age in various population and have shown conflicting results. Therefore, Acharya et al., have conducted a study with modified Demirjian's method with addition of third molar and developed an Indian specific formula for the Indian population which gave more accurate results compared to the original French-Canadian population. ${ }^{22}$ Acharya's formula 
have been utilized in another study for the age estimation in South Indian children and the modified technique gave more accurate results. ${ }^{16}$ The limitation of this study would be that being a hospital based study, it may not be a true representative of Nepalese population.

\section{CONCLUSIONS}

In our study there was underestimation of the dental age by Demirjian's method and Nolla's method compared to the chronological age for both boys and girls. The applicability may vary due to genetic and ethnic variations between the population which may affect the tooth formation, development and the parameters used in different studies.Therefore further extensive studies are required with large number of samples for the population specific standards for the assessment of the dental age.

\section{ACKNOWLEDGEMENTS}

Gratitude is expressed to Department of Oral Medicine and Radiology, Nepal Medical College, Attarkhel, Jorpati, Kathmandu, Nepal.

\section{REFERENCES}

1. Sachan K, Sharma VP, Tandon P. Reliability of Nolla's dental age assessment method for Lucknow population. Journal of Pediatric Dentistry. 2013;1(1): 8-13. [Full text]

2. Cugati N, Kumaresan R, Srinivasan B, Karthikeyan P. Dental age estimation of growing children by measurement of open apices: A Malaysian formula. $J$ Forensic Dent Sci.2015;7:227-31. [Full text]

3. Sinha S, Umapathy D, Shashikanth MC, Misra N, Mehra A, Singh AK. Dental age estimation by Demirjian's and Nolla's method: A comparative study among children attending a dental college in Lucknow (UP). J Indian Acad Oral Med Radiol.2014;26:279- 86. Full text

4. Baral P, Koirala B, Baral R, Bhattacharya S, Koirala S. Eruption Chronology of Primary Teeth in Nepalese Children. JNDA 2014;14(1): 1-6. [Full text]

5. Gupta A, Hiremath SS, Singh SK, Poudyal S, Niraula SR, Baral DD, Singh RK. Emergence of Primary Teeth in Children of Sunsari District of Eastern Nepal. McGill Journal of Medicine2007; 10(1):11-15. [Pubmed]

6. Upadhyay S, Shrestha R, Shrestha D, Poudyal S. Permanent Teeth Emergence Time and Sequence in Children of Kavre District, Nepal. Kathmandu Univ Med J 2016; 55(3) 269-73. [Pubmed]

7. Kiran S, Sharma VP, Tandon P, Tikku T, Verma S, Srivastava K. To establish the validity of dental age assessment using Nolla's method on comparing with skeletal age assessed by hand wrist radiographs. J Orthod Res 2013; 1:11-5. [Full text]

8. Prabhakar AR, Panda AK, Raju OS. Applicablity of Demirjian's method of age assessment in children of Davengere. J Indian Soc Pedo Prev Dent 2002;20(2):54-62. [Pubmed]

9. Elamin F, Liversidge HM. Malnutrition has no effect on the timing of human tooth formation. PLos ONE 2013; 8(8):e72274. Doi:10.1371/ journal.pone.0072274.[Full text]

10. Demirjian A, Goldstein H, Tanner JM. A new system of dental age assessment. Hum Biol 1973; 45:211-7. [Full text]

11. Gupta R, Rajvanshi H, Effendi H, Afridi S, Vuyyuru KK, Vijay B, Dhillon M . Dental age estimation by Demirjian's and Nolla's method in adolescents of western Uttar Pradesh. Journal of Head \& Neck physicians and surgeons. 2014;3 (1):50-6. [Full text]

12. Altunsoy M, Nur BG, Akkemik O, Ok E, Evcil MS. Dental Age Assessment: Validity of the Nolla Method in a Group of Western Turkish Children. Marmara Dental Journal. 2013; 2: 4952. [Full text]

13. AS Panchbhai. Dental radiographic indicators, a key to age estimation. Dentomaxillofacial Radiology 2011; 40:199-212. [Pubmed]

14. Priyadarshini C, Puranik M P, Uma S R. Dental Age Estimation Methods: A Review. Int $J A d v$ Health Sci 2015;1(12):19-25. [Full text]

15. Savita JK, Kumar BNY, Mamatha NS. Teeth as age estimation tool in children and adolescents. J Med Radiol Pathol Surg 2017;4:12-15. [Full text]

16. NyachhyonR : Evaluation of Dental Age in Nepali Children using Demirjian's 7-Teeth Method. Orthodontic Journal of Nepal2017;7 (2):37-40. [Full text]

17. RB Mohammed, $B$ Srinivas, $P$ Sanghvi, G Satyanarayana, M Gopalakrishnan, BV Pavani. Accuracy of Demirjian's 8 teeth method for age prediction in South Indian children: A comparative study.Contemp Clin Dent. 2015 Jan -Mar; 6(1): 5-11. [Pubmed]

18. Koshy S, Tandon S. Dental age assessment: the applicability of Demirjian's method in South Indian children.Forensic Sci Int. 1998 ;94:73-85. [Pubmed]

19. Willems G, Van Olmen A, Spiessens B, Carels 
Khanal et al. Dental Age Estimation by Demirjian's and Nolla's Method in Children..

C. Dental age estimation in Belgian children: Demirjian's technique revisited. J Forensic Sci 2001;46(4):893-895. [Pubmed]

20. A Jurca,Lazar L, Pacurar M, Bica C, Chibelean M, Bud E. Dental Age Assessment Using Demirjian's Method - A Radiographic Study. European Scientific Journal. 2014;10(36) :5160. [Full text]

21. Nur B, Kusgoz A, Bayram M, Celikoglu M, Nur M, Kayipmaz S, Yildirim S. Validity of Demirjian and Nolla methods for dental age estimation for Northeastern Turkish children aged 5-16 years old. Med Oral Patol Oral Cir Bucal. 2012 Sep 1;17 (5):e871-7. [Full text]

22. Patel P, Agarwal N, Agravat D, Ashutosh, Manjunath SM, Patil P. Applicability of DemirjianTechnique of Age Estimation on Children and Adolescents of Ahmedabad City. $J$ Adv Med Dent Scie 2014;2(2):37-41. [Full text]

23. Acharya AB. Age estimation in Indians using Demirjian's 8-teeth method. $J$ Forensic Sci. 2011;56:124-7. [Pubmed]

Citation: Khanal S, Acharya J, Shah P. Dental Age Estimation by Demirjian's and Nolla's Method in Children of Jorpati, Kathmandu. JCMS Nepal. 2018;14(3):137-41 